This is the author's final, peer-reviewed manuscript as accepted for publication. The publisher-formatted version may be available through the publisher's web site or your institution's library.

\title{
Aerobic exercise is promoted when individual performance affects the group: a test of the Kohler motivation gain effect
}

Brandon C. Irwin, Jennifer Scorniaenchi, Norbert L. Kerr, Joey C. Eisenmann, Deborah L. Feltz

\section{How to cite this manuscript}

If you make reference to this version of the manuscript, use the following information:

Irwin, B. C., Scorniaenchi, J., Kerr, N. L., Eisenmann, J. C., \& Feltz, D. L. (2012).

Aerobic exercise is promoted when individual performance affects the group: A test of the Kohler motivation gain effect. Retrieved from http://krex.ksu.edu

\section{Published Version Information}

Citation: Irwin, B. C., Scorniaenchi, J., Kerr, N. L., Eisenmann, J. C., \& Feltz, D. L. (2012). Aerobic exercise is promoted when individual performance affects the group: A test of the Kohler motivation gain effect. Annals of Behavioral Medicine, 44(2), 151-159.

Copyright: (c) The Society of Behavioral Medicine 2012

Digital Object Identifier (DOI): doi:10.1007/s12160-012-9367-4

Publisher's Link: http://www.springerlink.com/content/u550466163208027/

This item was retrieved from the K-State Research Exchange (K-REx), the institutional repository of Kansas State University. K-REx is available at http://krex.ksu.edu 
Aerobic exercise is promoted when individual performance affects the group: A test of the Kohler motivation gain effect

\author{
Brandon C. Irwin Jennifer Scorniaenchi Norbert L. Kerr \\ Joey C. Eisenmann Deborah L. Feltz \\ Michigan State University
}

Correspondence concerning this article should be addressed to Brandon C.

Irwin, Kinesiology, Michigan State University, IM Sports-Circle, East Lansing, Michigan, 48824. Phone \# (517)-353-4868. Fax \# (517)-353-2944. Electronic mail may be sent via Internet to birwin@msu.edu

\title{
Acknowledgements
}

The authors wish to thank Sara Sherman and Kaitlynn Osborn and for their contributions in the execution of this study. 


\begin{abstract}
Background: A key barrier to achieving recommended intensity and duration of physical activity is motivation.

Purpose: We investigated whether a virtually-present partner would influence participants' motivation (duration) during aerobic exercise.

Method: Fifty-eight females $\left(M_{\text {age }}=20.54 \pm 1.86\right)$ were randomly assigned to either a coactive condition (exercising along side another person, independently), a conjunctive condition (performance determined by whichever partner stops exercising first) where they exercised with a superior partner, or to an individual condition. Participants exercised on a stationary bike at $65 \%$ of heart rate reserve on 6 separate days.

Results: Across sessions, conjunctive condition participants exercised significantly longer $(M=21.89 \mathrm{~min}, S D= \pm 10.08 \mathrm{~min})$ than those in coactive $(M=19.77 \mathrm{~min}, S D= \pm$ $9.00 \mathrm{~min})$ and individual $(M=10.6 \mathrm{~min}, S D= \pm 5.84 \mathrm{~min})$ conditions $(\mathrm{p}<0.05)$.
\end{abstract}

Conclusion: Exercising with a virtually-present partner can improve performance on an aerobic exercise task across multiple sessions.

Keywords: Group performance, group exercise, exergame, Köhler effect, motivation, exercise partner 


\section{INTRODUCTION}

Many people are physically inactive even though the links between regular physical activity and health are well documented [1-5]. A number of psychological factors have been proposed that influence motivation to exercise, including enjoyment [6], self-efficacy [7], and social influence [8]. One promising but understudied factor is exercising in groups. For example, group exercise programs have been shown to lead to higher exercise adherence than individualized programs [9]. However, group exercise programs may not be helpful to people whose time conflicts with scheduled exercise programs, those who do not have the resources, or those who suffer from social physique anxiety [10]. Moreover, few such programs make the group members interdependent in any way. Considerable basic laboratory research has shown that having people work together at a task can, under the right conditions, reliably boost their task motivation $[11,12]$. The best documentation of such group motivation gains is the Köhler effect $[13,14]$ - compared to working individually, the weaker member of the group tends to be more motivated when working together with a moderately more capable partner, especially when the group's final level of performance depends primarily upon the weaker member (i.e., when the group task has conjunctive task demands [15]. This motivation gain appears to arise from two processes - a tendency to strive to match or exceed the performance of one's more capable partner (via social comparison process [16]) and a tendency to work harder when the group's outcome (and/or one's evaluation by the group) hinges crucially on one's own level of effort (via an indispensability process) [17]. 
One particularly promising way in which these processes might be harnessed to boost motivation to exercise is with virtually-present exercise partners. With a virtuallypresent partner, one could avoid certain limitations of face-to-face group exercise programs (e.g., for scheduling; for finding the optimal exercise partner) and social anxiety about one's physique. Moreover, when one's partner is only virtually present, one need not risk losses in motivation for a real, more-capable partner via the same processes that boost motivation for the less capable partner. Recently, Feltz and colleagues [18] reported the first empirical attempt to demonstrate a Köhler motivation gain in exercise groups with virtually-present partners. They reported a $24 \%$ increase $(d=.99)$ in performance at a series of five isometric exercises by people working with a more capable, virtually-present partner compared to controls exercising individually. This impressive motivation gain was achieved without any observable increase in subjective effort, decrease in interest in the task or intention to exercise in the future.

The present study seeks to extend these promising results in a couple of ways. First, although isometric exercise can be effective at improving muscular strength, continuous aerobic exercise is more functional for promoting health (e.g., weight loss; cardio-pulmonary function) [19]. Thus, in the present study, an aerobic exercise task was used (viz. peddling an exercise bike). Second, unlike previous laboratory studies [13], Feltz et al. [18] found that motivation gain was entirely due to social comparison - that is, making the task into a conjunctive group task did not boost effort above that level obtained with coacting but otherwise independent exercisers. They speculated that this may have been because their one-time exercise session was approached by their participants as an inherently competitive — not as a collaborative_-task setting. They 
suggested that repeated opportunities to exercise with a teammate might boost the relative importance of being an indispensible, "weak link" in the group, perhaps by strengthening one's concern for and identification with one's group [20]. Of course, to be effective, any intervention designed to boost motivation to exercise must do so not just once, but repeatedly. Therefore, in the present study we examined exercise groups that worked out together repeatedly (over five sessions). Following Feltz et al.'s reasoning, we hypothesized that the more often one exercised conjunctively with a partner, the more important one's indispensability to that group would become, and the larger the resultant Köhler motivation gain.

\section{METHODS}

\section{Participants}

Participants were recruited from university-based physical activity courses. Participants were screened for physical fitness and habitual physical activity levels, which were assessed with two self-report items, respectively: Self reported fitness, ("How would you rate your personal fitness level?" on a 5-point scale, 1 = poor, $3=$ average 5 = excellent) and Self reported physical activity, ("How many times per week do you exercise for 30 continuous minutes or more at a moderate to high intensity?" on a scale from 0 to 7 or more). The majority of the participants rated their current fitness level as average (44.8\%) or good $(32.9 \%)$. Seven students who were self-categorized as "highly active" (at least 30 continuous minutes or more of exercise at a moderate to high intensity more than 7 times a week) were excluded from the study because it was assumed that if they were highly active individuals it was likely that they were highly motivated in regards to exercise, which was not the specific target group for this study. 
From the initial screening, sixty female college students were selected for participation in the study. Two people dropped out before their first appointment, resulting in a final sample of fifty-eight $\left(M_{\mathrm{age}}=20.54, S D= \pm 1.86\right)$. Females were used for several reasons. First, Feltz et al. [18] found no gender differences in their initial study of the Köhler effect in exercise groups (although see Kerr et al. [17] for possible exceptions to this rule). Second, there were many more females than males in our participant pool. Third, there is evidence that women exercise at less vigorous intensities compared to men [21], and therefore may warrant specific study on motivation to exercise.

All participants either received an excused absence as an incentive to participate $(n=49)$ or course credit $(n=9)$. No one participated without one of these incentives. Sample size was determined from a power analysis conducted by the researchers, which followed $\mathrm{f}$ index recommendations and suggested that a moderate $(f=.30)$ Köhler effect would be observed with a probability $>.80$ with this sample size. Participants were screened using the Physical Activity Readiness Questionnaire and asked to provide some basic demographic information. Prior to data collection all participants signed a written consent form. The study was approved by the Michigan State University Institutional Review Board.

Finally, prior to their first session, participants were provided instructions on how to calculate their resting heart rate (i.e. after they wake up in the morning while still in bed, and preferably the average of 2 different days). Resting heart rate and age were used to calculate $65 \%$ of individual participant heart rate reserve using the Karvonen formula: Heart rate reserve $=((220$-age $)-$ resting heart rate $) \times$ Intensity $\%+$ resting heart rate. 


\section{Research Design and Procedures}

There were two experimental conditions (coactive and conjunctive) and an individual control condition. Participants were randomly assigned to one of the three conditions after an initial baseline pretrial. The core research design was a 3 x 5 (Groups $\mathrm{x}$ Trial) factorial design with repeated measures on the second factor. There were relatively equal numbers in all conditions $($ coactive $=18$, conjunctive $=20$, individual $=$ 20).

Participants were asked to ride a video-game exercise bike for as long as they felt comfortable. We used the Expresso Fitness Bike, which has a computer-supported display that enables participants to ride on outdoor terrain virtually. The bike monitor displayed information on ride duration, power output, and heart rate. All participants rode the same course for all trials. For all three conditions-individual control, conjunctive, and coactive — each individual rider's intensity level was predetermined on the Expresso fitness bike based on the bike gear they were able to ride at and reach $65 \%$ HRR while maintaining 70 rpm for 3 minutes.

\section{Procedure}

Those who were eligible to participate signed up for six 60-minute sessions within a 4-week time frame with a maximum of 3 sessions per week and a minimum of $24 \mathrm{hr}$ between sessions. The initial session (Trial 1) was used to obtain baseline data for all participants. Participants first completed the Intention to Exercise scale (these and other measures are described in more detail below). Participants were then shown how to properly wear the heart rate monitor (Polar E600) and then fastened and secured the measuring transmitter around the chest. The bike was then adjusted (viz., seat height, 
distance from handlebar); this same position was used on all subsequent trials.

Participants were given 2 min to warm up at the lowest gear and were told to keep the cadence between 66 and $74 \mathrm{rpm}$ and ideally at 70, using the metronome to help keep pace; they could also monitor their rpm on the bike screen. At the end of the 2-min warmup, the participant's heart rate was checked. If they had not achieved $65 \% \mathrm{HRR}$, the experimenter increased the gear by one level every $10 \mathrm{~s}$, for up to $3 \mathrm{~min}$, until the participant reached $65 \%$ HRR. If the participants' heart rate rose above $65 \%$ HRR during the $3 \mathrm{~min}$ period, the gear was decreased by one level every $10 \mathrm{~s}$ until they achieved steady state at $65 \%$ HRR. Participants were told that they must attempt to stay within the interval of 66-74 rpm at all times. The gear that the participant ended with was recorded and represented their intensity level or "working gear" that would remain the same for all trials.

Participants were then given a 3 min rest period during which the experimenter gave a description of the next phase of the session in which they would ride the bike for as long as they could at $65 \%$ HRR using the working gear while maintaining between 66$74 \mathrm{rpm}$. If the participant dropped below $66 \mathrm{rpm}$ for longer than $5 \mathrm{~s}$, she would be notified "Strike One." If it happened a second time the participant would hear "Strike Two," and if it happened a third time she would be notified "Strike Three, Your Trial Is Over." Participants were also told that they could choose to stop riding at any point during their trial, regardless of whether or not they had any strikes at all, by saying 'I'm done." The metronome was then turned on, and the time was started. Subjective effort (Ratings of Perceived Exertion) was obtained every $3 \mathrm{~min}$. At the end of the ride, the time, average heart rate, average power output, and the method of stoppage (Strike Out or 
Quit) were recorded. The participant removed the heart rate monitor and completed the intention to exercise scale and a self-efficacy scale.

After the initial pretest trial was completed, participants were randomly assigned to the individual, conjunctive, or the coactive conditions where they remained for the subsequent five trials. In all remaining trials, those who were assigned to be in the individual group rode the bike under the same conditions and instructions as they did during the pretest trial, except they were given a 5 min warm-up at half of their working gear before the start of the trial.

In all remaining trials, participants assigned to the conjunctive or coactive condition were assigned a "virtually-present partner" as their teammate for the ride and were told that their partner was scheduled to ride at the same time as they were, on another Expresso fitness bike in another lab. At that point, one of two randomly-assigned female confederates (Stacey or Laura) was "introduced" to the participant through a brief video-chat (Skype) session that was ostensibly live but was, in fact, pre-recorded using a confederate; the protocol was the same as in previous studies using a similar apparatus [18]. The participant sat in front of a laptop computer where she saw the image of her unspeaking partner in a Skype window. The experimenter gave some brief instructions for how the interaction would proceed, instructing the participant and partner to share her year in school, major, career plans and favorite TV show. As the experimenter distracted the participant by saying "Stacy/Laura, why don't you go first?", the experimenter, using a remote control in his/her pocket, also started the video clip in which the partner spoke. The partner's responses were unexceptionable (viz., s/he was a sophomore, undecided on a major, not sure about career plans, and liked to watch American Idol and re-runs of 
Friends). Once the partner was done, the participant was instructed to share the same information. The interaction was thus highly structured and deviations from the scripted procedure were rare. After both had spoken, the experimenter instructed both the participant and partner to go sit in a chair that was positioned away from the Skype laptop in their respective laboratories.

Participants were then given false feedback regarding her partner's performance on the pretest Trial 1 . The pretest Trial 1 performance of the partner was fabricated to always be moderately better than the participant's, whereby the research assistant told the participant that her partner rode a duration between 8 and 12 minutes longer than she (e.g. "Your partner rode 9.5 minutes longer than you"). During the actual trial, participants were able to track their partner's progress by watching the partner ride on an ostensibly live video feed. Actually, this video was previously recorded and looped so that the virtual partner never stopped riding until the participant quit.

Participants in the conjunctive condition had the same virtual partner (recorded in several different clothing outfits and hair-styles) for all five trials. The procedures and stimulus materials were exactly the same for the coactive and conjunctive condition, except participants in the conjunctive condition were told that the team's score would be the time of the partner who stopped riding first (either because she chose to stop or because she accumulated " 3 strikes" due to letting her heart rate drop), at which point the trial would end for both partners. In the coactive condition, the two riders were not on a team (i.e. no task interdependence), there was no team score, and participants were told that each of the partners could continue for as long as they could, regardless of the other's performance. 
Participants in both the conjunctive and coactive conditions were not provided with any means to communicate with their partners, other than the initial video-chat introduction. Self-efficacy for all groups was assessed both at the beginning and end of Trials 2-6 (as well as the baseline measurement taken at the end of Trial 1). Intention to exercise was assessed at the beginning of Trial 1 and at the end of the Trial 6.

\section{Outcome Measures}

Self-efficacy. Self-efficacy was measured following Bandura's [22] guidelines and consisted of 12 items that asked participants to assess the degree of confidence they have in their ability to cycle at the pre-determined intensity for 10 hierarchically ordered number of minutes. In order to avoid floor and ceiling effects, intervals were $5 \mathrm{~min}$ increments as determined from pilot testing. Baseline self-efficacy was assessed prior to Trial-1 and included the stem, "Rate your confidence right now that you can cycle for...".and then again after each trial with the stem, "Rate your confidence that the next time you cycle, you could cycle for..." Responses were made on an 11-point scale, ranging from 0 (not at all confident) to 10 (completely confident). Efficacy scores for each session were computed by averaging the 12-items.

Intention to exercise. Intention, adapted from the scale used by Mohiyeddini, Pauli and Bauer [23], was measured with two items: "My goal is to exercise tomorrow for at least 20 minutes" and "I intend to exercise tomorrow for at least 20 minutes." Ratings were made on a 7-point scale, from -3 (not at all true for me) to +3 (completely true for me). The two items were averaged for an intention score.

Ratings of perceived exertion. Perceived exertion was measured using the Borg Ratings of Perceived Exertion scale during each cycling trial [24]. The rating category 
scale used in this study was a 1 to 10 scale (very easy to extremely hard). Every 3 min, the participants were prompted to say which number corresponded with their level of exertion. If the participant did not ride for at least 3 minutes they were asked to rate their perceived exertion for the last 30 seconds that they were riding the bike. The average of all ratings within each trial were computed for a perceived exertion score.

Power output. After each trial was completed, the participant's power output was recorded from the reading on the Expresso fitness bike screen. The recorded power output was the average of the instantaneous power output throughout the session. The power output gave researchers a measure of the actual intensity of the task, which, given the equating of task difficulty and maintenance of heart rate in a narrow range, should have remained constant across participants, and hence, across conditions.

\section{RESULTS}

\section{Preliminary Analyses}

Two participants were excluded from analysis; one sustained an injury outside of the study and the other raised concerns about the confederate being too young and an unrealistic match. A one way ANOVA with self reported fitness showed no significant differences between conditions. However, a second one-way ANOVA with self-reported physical activity revealed a significant condition effect, $F(2,55)=3.22, p=.048$,

$\eta_{\mathrm{p}}{ }^{2}=.105$; Newman-Keuls post-hoc tests showed that the conjunctive mean was significantly higher than that for the coactive condition (see Table 1). Thus, it is possible that despite random assignment, there were condition differences in initial physical activity, although the weak validity coefficients for self reported fitness measures $[25,26]$ argues against this. In any case, in the primary analyses on the baseline performance 
measure at Trial 1 - which should capture any individual or condition differences in initial fitness - was used as a covariate; it is also noteworthy that there were no betweencondition differences in this variable, $F(2,55)=1.88$.

\section{Adherence to exercise protocol and potential training effects.}

The gears were set so that the difficulty of the task was equated across participants. So, as long the prescribed rpm range, heart rate and instantaneous power intensity level were maintained, the difficulty of the task should have been comparable across participants, and hence, there should also have been no between-condition effects for these variables. And, unless participants systematically altered where in the prescribed range they pedaled or actually became more or less fit as trials progressed, these variables should also have been steady across successive trials. To explore this possibility, separate 3 (condition) x 5 (trial: 2, 3, 4, 5, and 6) ANCOVAs (where the latter was a within-Ss factor) were run on both the power output and heart rate data. Since there still could be individual differences within-condition in how high or low within the prescribed range a participant chronically persisted, baseline (Trial 1) power output and heart rate were used as covariates in these analyses.

Neither condition $(p=.83)$ nor trial $(p=.25)$, nor their interaction $(p=.50)$ significantly affected average power output. As expected, participants displayed a constant level of work intensity across the sequence of trials and across the three experimental conditions. For heart rate, the only significant effect was a trial main effect, $F(4,216)=2.45, p=.047, \eta_{\mathrm{p}}{ }^{2}=0.043$. The biggest change in heart rate occurred between Trial 2 (the first regular trial, after the pretest at Trial 1) and Trial 3, after which mean heart rate remained fairly steady. 


\section{Exercise Performance}

The proportion of subjects who "quit" vs. those who "struck out" was $75 \%$ and $25 \%$, respectively. There were an equal number of subjects across conditions who quit, $\chi^{2}$ $(12)=11.93, p=.45, V=0.32$, and who struck out, $\chi^{2}(12)=10.35, p=.59, V=0.30$. A 3 (Condition: individual, coactive, conjunctive) x 5 (Trials 2-6) mixed ANCOVA of performance was conducted with Trial as a within-subjects factor and Trial 1 baseline performance as a covariate. First, there was a significant condition main effect, $F(2,54)$ $=22.07, p<.001, \eta_{\mathrm{p}}{ }^{2}=.45$. Participants persisted longer when working alongside a more capable coactor (adjusted mean=1090.59 s) than when working alone (adjusted mean = $731.87 \mathrm{~s}), t(54)=3.01, p<.01)$. This differences represents a robust $(d=.45) 49 \%$ improvement over individual performance. This gain in motivation to exercise was even greater $($ adjusted mean $=1481.06 \mathrm{~s}$, significantly higher than the coactive mean, $t(54)=$ $3.31, p<.01)$ among those exercising with a more capable partner under conjunctive group task demands, compared to individual controls, $t(54)=6.64, p<.001$. This represents an improvement of $102 \%(d=.94)$. This main effect was qualified by a significant Condition $\mathrm{x}$ Trial interaction effect, $F(8,216)=5.47, p<.001, \eta_{\mathrm{p}}{ }^{2}=.168$. Figure 1 shows that in every trial, participants in the coactive condition persisted $\sim 300$ s longer than the individual controls. This was verified in a follow-up analysis that dropped the conjunctive condition and found a significant coactive vs. individuals main effect, $F(1,35)=29.48, p<.001, \eta_{\mathrm{p}}^{2}=.457$, but no Trial $\mathrm{x}$ Condition interaction $(F<1)$. However, as hypothesized, the difference between the individual controls and participants in the conjunctive condition widened steadily from Trial 2 (439.6 s) to Trial 6 (1099.0 s); a follow-up analysis that dropped the coactive condition resulted in not only a strong 
conjunctive vs. individual main effect, $F(1,37)=34.78, p<.001, \eta_{\mathrm{p}}{ }^{2}=.485$, but also a robust interaction effect, $F(4,148)=8.06, p<.001, \eta_{\mathrm{p}}{ }^{2}=.179$. Planned contrasts within trial-by-trial analyses also revealed that at Trial 2, both the conjunctive (1224.8 s) and coactive $(1104.7 \mathrm{~s})$ conditions were significantly $(p$ 's $<.002)$ higher than the individual controls (785.1 s), but did not differ from one another. However, from Trial 3 on, the gain in performance observed in the conjunctive condition was significantly $(p$ 's $<.025)$ and increasingly larger than that observed in the coactive condition. By the $6^{\text {th }}$ and final trial, participants in the conjunctive condition were pedaling $1721.6 \mathrm{~s}(28.7 \mathrm{~min})$, which was $177 \%$ longer than the individual controls (622.6 s), an effect size of $d=1.38$.

Ratings of Perceived Exertion. To assess differences in subjective effort, a 3 (condition) x 5 (trial: $2,3,4,5, \& 6$ ) ANCOVA was run with Trial 1 baseline perceived exertion as a covariate. A significant trial effect was found, $F(4,212)=2.835, p=0.025$, $\eta_{\mathrm{p}}{ }^{2}=0.051$; subjective effort ratings tended to decline across trials (only the linear trend was significant, $p<.02$, among the polynomial trend contrasts). However, there was neither a condition main effect nor Condition $\mathrm{x}$ Trial interaction $(p$ 's $>.52)$.

Task Self-Efficacy. A 3 (condition) x 5 (trial) ANCOVA was run with baseline self-efficacy as the covariate and post-trial self-efficacy as the dependent variable. First, there was a significant trial effect, $F(4,196)=2.809, p=.027, \eta_{\mathrm{p}}{ }^{2}=.054$ : self-efficacy tended to increase across trials. There was also a condition effect, $F(2,54)=3.21, p$ $\left.=.049, \eta_{\mathrm{p}}{ }^{2}=0.12\right)$; self-efficacy was lowest in the individual control condition (4.66), intermediate in the coactive condition (5.33), and highest in the conjunctive condition (5.84). Only the individual and conjunctive conditions differed significantly $(p=.015)$. 
Intention to exercise. A one-way ANOVA using pre-trial intention showed that participants expressed a moderately positive intention $(M=1.75, S D=1.62)$ that did not differ between conditions $(F<1)$. A pre-post change score was computed and analyzed to see whether the performance differences we observed across conditions were accompanied by changes in intention to continue to exercise. A one-way ANOVA on these change scores revealed a significant condition effect, $F(2,55)=9.47, p<.001, \eta_{p}{ }^{2}$ $=.256$. Participants in the individual control condition, who had exercised the least vigorously of all three conditions, showed a marked and significant decline in their intent to exercise $(M=-2.15, S D=1.98)$. In contrast, the participants in the two conditions with partners showed little decline $\left(M_{\text {coactive }}=-.056, S D=1.43 ; M_{\text {conjunctive }}=-.100, S D=1.68\right)$; neither was significantly different than zero or from one another, but both were significantly larger $(p ’ s<.01)$ than the individual controls $(M=-2.15, S D=1.98)$.

\section{DISCUSSION}

The primary aim of this study was to determine whether the Köhler motivation gain effect could be harnessed to enhance continuous aerobic exercise on repeated sessions using a virtually-present partner. Additionally, the study compared the relative strength of effects attributable to each of the two underlying mechanisms of the Köhler effect (social comparison and indispensability) on an aerobic exercise task over multiple sessions. The results showed that those who cycled with a more-capable virtually-present partner under coactive task demands persisted $548.1 \mathrm{~s}$ longer on average across sessions (raw score $M=1186.1 \mathrm{~s}$ ) than individuals cycling alone (raw score $M=638.1 \mathrm{~s}$ ). [Note that we are focusing on raw performance scores here, which produces slightly different estimates of effect size than for the analyses of performance scores corrected for baseline 
performance, as presented in the Results section.] This represents more than a 9.14 min $(86 \%)$ increase on individual exercise. Further, those who cycled with a partner under conjunctive conditions (raw score $M=1313.46 \mathrm{~s}$ ) persisted $675.4 \mathrm{~s}$ longer than individual controls and $127.34 \mathrm{~s}$ longer than those under coactive conditions. This represents an additional $2.1 \mathrm{~min}$ increase beyond those in the coactive condition, and a $100 \%$ improvement on individual exercise. These results indicate the overall gain; the effect of working conjunctively was observed to increase across trials. If we focus on the final trial when that effect was at its maximum, the conjunctive participants were pedaling $19 \mathrm{~min}$ (208\%) longer than those exercising individually.

To equate task difficulty, all participants exercised at a minimum intensity of $65 \%$ of heart rate reserve and $70 \pm 4 \mathrm{rpm}$. Although all participants were able to maintain these intensities, we observed a significant decrease in heart rate across sessions, for which there are at least two explanations. The first and most plausible explanation is that with a little practice, participants learned how to maintain the bottom of the prescribed rpm range without "striking out." A second possibility is that this was a genuine training effect — with accumulated training on the bike, one might get fitter, making it easier to maintain what had been one's $65 \%$ heart rate reserve at pretest. However, it is implausible that such a training effect would emerge after a single trial (which, for the average participant, only lasted $17.4 \mathrm{~min}$ ), and that further training would show no additional benefit. Even if this drop in heart rate did reflect a genuine training effect, the more important point for us is that there was no such effect for experimental condition (overall nor moderated by Trial). Hence, any effects of condition on exercise performance - our primary interest — cannot be plausibly attributed to the task being or 
becoming noticeably easier (due to enhanced fitness) in any one condition vs. another, but rather were attributable to greater effort in the coactive and conjunctive conditions.

It is one strategy to create conditions that enhance a willingness to exercise.

However, such a gain might be difficult to sustain if those who showed the gain also felt wholly exhausted by their efforts and/or developed an aversion to either the particular exercise task or to exercising more generally. This was not the case in this study. Even though participants were exercising much longer in the experimental conditions, the perceived exertion values were no higher than those provided by the individual controls. This is important, given the demonstrated negative relationship between subjective intensity effort and motivation to exercise [27]. Moreover, participants' confidence that they could persist at the immediate cycling task mirrored their actual performance- - the conjunctive task conditions, which produced the greatest gains in effort, also boosted such confidence significantly (relevant to the individual controls). Finally, self-reports of intention to exercise in the future were significantly higher in both experimental conditions than among controls. These results are encouraging, and suggest that the gains we observed over a half-dozen hour-long sessions could be sustained in a longer-term program of exercise.

Being able to more than double one's performance is a substantial gain for those trying to increase their physical activity. The observed effect sizes (over all trials, conjunctive $d=.66$, coactive $d=.50$; at Trial 6 , conjunctive $d=1.80$, coactive $d=.90$ ) compare very favorably with other interventions designed to increase physical activity (e.g., Williams \& French [28] report an average effect size of $d=.21$ in a recent metaanalysis of 27 physical activity intervention studies). Thus, the findings of the current 
study may be of particular value in future efforts to help people meet physical activity recommendations.

In most respects, the present findings corroborate the patterns observed in prior research. In particular, the ultimate superiority of the conjunctive task condition to either coactive or individual conditions corroborates a number of prior studies that have shown a significant indispensability effect $[14,17]$. However, there are a few intriguing differences. First, there was no such indispensability effect at first -i.e. conjunctive $=$ coactive at an initial session of group exercise - in the present study and in a previous exercise study [18]. Feltz et al. [18] speculated that (a) exercising with others might be inherently competitive, bolstering social comparison and undermining concerns about the indispensability of one's efforts, but (b) the relative importance of these two processes might reverse with repeated experience in an exercise group. The current findings are consistent with these speculations. Second, Lount et al. [20] found that the combined motivation-enhancing effect of the social comparison and indispensability mechanisms attenuated across multiple trials with the same partner, whereas we observed the opposite pattern (the combined effect grew with repeated trials). Lount et al. [20] speculated that repeated comparisons with a consistently more capable partner would be discouraging and convince one that successful matching of that partner's performance was an unattainable goal, but that even if there were little or no reason to strive in order to compare favorably with one's partner, under conjunctive conditions one would always feel some degree of indispensability. However, in the present study, we found no attenuation of the social comparison effect with repeated trials, and observed not a constant but an enlarging indispensability effect. 
We believe that these apparent anomalies can be attributed to three distinctive aspects of the present experiment. First, in most of the prior Köhler studies, including Lount et al. [20], participants persisted at laboratory tasks that were of no special interest or importance to them (e.g., holding a weight as long as possible; working at a repetitive business simulation). In the present study, by contrast, participants were students enrolled in physical activity courses who probably wanted to maintain or improve their level of activity or fitness. It seems likely that you would persist in trying to match a superior coactor for longer at a task that was important to you (e.g., of greater intrinsic interest, of greater relevance to salient personal goals or to self esteem) than one that was unimportant to you. Second, unlike prior studies, via the calibration of bike gear to heart rate in Trial 1, we functionally equated task difficulty for all participants. This meant that differences in performance between one's self and one's partner could not be readily attributed to differences in ability— those differences had been controlled for by making the task more difficult for those who were in better shape-but could more readily be attributed to differences in effort. Essentially, in the present study the apparent superiority of one's partner was probably not due to differences in stable, uncontrollable ability, but in unstable, controllable effort [29]. It seems more likely that one would stop trying to keep up with a more superior coactor after repeated failures to do so if that coactor's superiority were attributed to greater ability [20] than to greater effort (as we speculate occurred here). Third, in most prior studies [20], participants were strangers to one another and interacted minimally. By contrast, in the present study, participants in the experimental conditions "met" their partner at the initial session, exchanged personal information (that established similarities in age, education, and general interests), and 
then observed her striving in every subsequent session. The indispensability effect shows that it is motivating to be the "weak link" in a team working at a conjunctive task. It seems likely that repeated collaborations over a span of days with a known partner (as in the present study) would bolster this indispensability effect more than collaborations with an anonymous partner over a span of minutes (as in Lount et al. [20] and most prior studies). Thus, we speculate that the Köhler effect is likely to be stronger when (a) task difficulty is equated between group members, (b) group members care more about good task performance, and (c) group members care more about their group, and suggest that these features may help explain the particularly large motivation gain observed here $(d=$ .94) compared to the typical Köhler effect study (meta-analytic estimate of mean $d=.60$ ) [14]. There is now some empirical support for the importance of group member relations $[17,30,31]$, but little direct evidence bearing on the first two proposed moderating variables. Besides these factors, Feltz et al. [18] suggest that additional promising areas for investigation include (a) the effects of encouragement from the partner, (b) similarity in appearance and age of the partner, and (c) the degree to which the partner is live vs. completely virtual.

One limitation of this study was the lack of evidence that the subjects believed in the authenticity of their virtual partner. While previous research in our lab has found this manipulation to be highly successful [18], there is indeed a significant limitation in not having evidence of the effectiveness of the manipulation. The strongest evidence we have is that (a) we observed the anticipated pattern of behavior (i.e., performance) across trials and between conditions and (b) that the subjects did not raise any concerns towards the authenticity of the partner during the actual laboratory exercise sessions. Secondly, while 
nine participants received an excused absence in their 1-credit activity class as an incentive for their participation, this tally was not linked to specific participants and thus it is not clear that they were evenly distributed across conditions, but still their assignment was random.

Lastly, the current study was conducted in a laboratory setting. While researchers have recently observed motivation gains in sequential group tasks in the field using archival data (e.g. swimming relays [32]), there are no known studies or interventions that intentionally harness the Köhler effect to increase motivation in real world tasks and environments. Although research in this area is relatively young, future research should examine the utility and feasibility of implementing such strategies.

\section{Conclusion}

The current study provides encouraging results regarding the utility of the Köhler motivation gain phenomenon in task groups. Whereas much prior work has examined how to reduce motivation losses in groups [12], the current findings contribute to a growing body of research on the existence and performance of motivation gains in experimental groups, and the likely utility of these gains, in this case, in aerobic exercise tasks. These findings lend support to the notion that group motivation gain effects can influence exercise performance (most potently under conjunctive task demands with a moderately more capable partner) over several trials. Finally, the current study lends support for the use of virtually-present partners to achieve such motivation and performance gains, and encourages further research on group exercise in video health games.

Conflict of Interest Statement: The authors have no conflict of interest to disclose. 
Table 1.

Means of primary measures by condition.

$\frac{\text { Individual }}{M(S D)} \quad \frac{\text { Coactive }}{M(S D)} \quad \frac{\text { Conjunctive }}{M(S D)}$

Fitness \& Physical

Activity

$\begin{array}{llll}\text { SRPA (d/wk) } & 3.0(1.6) & 2.7(1.1) & 3.9(1.6) \\ \text { SRF } & 3.3(1.1) & 3.4(0.6) & 3.3(0.7)\end{array}$

Adjusted performance

means $(\mathrm{s})^{\mathrm{a}}$

$\begin{array}{llll}\text { Trial 2 } & 785.1 & 1104.7 & 1224.8 \\ \text { Trial 3 } & 776.3 & 1201.2 & 1442.9 \\ \text { Trial 4 } & 779.1 & 1067.0 & 1468.1 \\ \text { Trial 5 } & 696.1 & 1081.3 & 1547.9 \\ \text { Trial 6 } & 622.6 & 998.7 & 1721.6 \\ \text { Total } & 731.9 & 1090.6 & 1481.1\end{array}$

Raw score

performance means

(s)

\begin{tabular}{llll} 
Trial 1 & $633.1(399.9)$ & $910.1(626.6)$ & $689.9(324.4)$ \\
Trial 2 & $682.1(447.6)$ & $1272.1(649.5)$ & $1177.2(486.2)$ \\
Trial 3 & $670.8(409.8)$ & $1372.6(564.1)$ & $1394.1(673.8)$ \\
Trial 4 & $686.5(417.3)$ & $1217.8(568.2)$ & $1425.3(847.9)$ \\
Trial 5 & $608.1(347.9)$ & $1224.2(546.9)$ & $1507.3(744.8)$ \\
Trial 6 & $548.0(326.3)$ & $1119.9(541.1)$ & $1687.2(889.0)$ \\
Total & $638.1(350.4)$ & $1186.1(539.8)$ & $1313.5(604.6)$ \\
\hline
\end{tabular}

Note: SRPA = Self-Reported Physical Activity; SRF = Self-Reported Fitness

${ }^{a}$ Adjusted means using Trial 1 as covariate $(\mathrm{T} 1=738.6 \mathrm{~s})$ 
Figure 1. Performance means across trials between conditions controlling for Trial 1 performance (s).

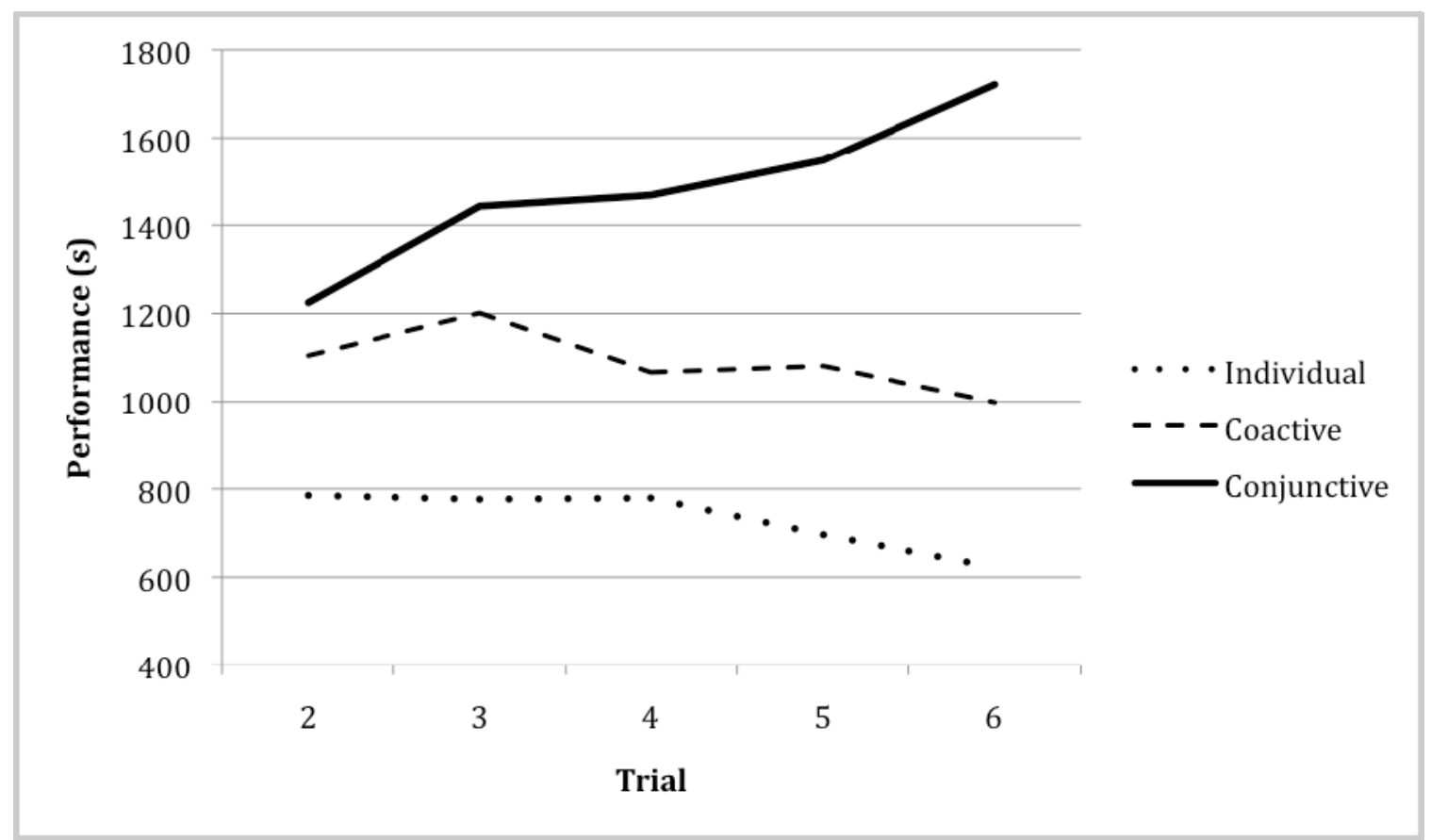




\section{Acknowledgements}

The authors wish to thank Sara Sherman and Kaitlynn Osborn and for their contributions in the execution of this study. All human studies have been approved by the MSU IRB and have therefore been performed in accordance with the ethical standards laid down in the 1964 Declaration of Helsinki. All persons gave their informed consent prior to their inclusion in the study. 


\section{References}

1. Chandrashekhar Y, Anand IS. Exercise as a coronary protective factor. Am Heart $J$. Dec 1991;122(6):1723-39.

2. Jennings GL, Deakin G, Dewar E, Jaufer E, Nelson LS. Exercise, cardiovascular disease and blood pressure. Clin Exp Hypertens. 1989;11:1035-52.

3. Lee IM. Physical activity, fitness, and cancer. In: Boucher C, Shephard RJ, Stephens T, eds. Physical activity, fitness, and health: International proceedings and consensus statement. Champaign, IL: Human Kinetics; 1994:814-31.

4. Warburton DE, Nicol CW, Bredin SS. Prescribing exercise as preventive therapy. CMAJ. Mar 28 2006;174(7):961-74.

5. Smith SC, Blair SN, Criqui MH, Fletcher GF, Fuster V, Gersh BJ, et al. Preventing heart attack and death in patients with coronary disease. $\mathrm{J}$ Am Coll Cardiol. Jul 1995;26(1):292-4.

6. Hardy CJ, Rejeski WJ. Not what, but how one feels: The measurement of affect during exercise. J Sport Exerc Psychol. 1989;11:304-17.

7. McAuley E, Courneya KS. Adherence to exercise and physical actiity as healthpromoting behaviors: Attitudinal and self-efficacy influences. Applied and Preventive Psychology. 1993;2:65-77.

8. Carron AV, Hausenblas HA, Mack D. Social influence and exercise: A metaanalysis. J Sport Exerc Psychol. 1996;18:1-16.

9. Dishman RK, Buckworth J. Increasing physical activity: a quantitative synthesis. Med Sci Sports Exerc. Jun 1996;28(6):706-19. 
10. Bain LL, Wilson T, Chaikind E. Participant perceptions of exercise programs for overweight women. Res Q Exerc Sport. 1989;60:134-43.

11. Baron RS, Kerr NL. Group process, group decision, group action. 2nd ed. Buckingham, UK: Open University Press; 2003.

12. Karau SJ, Williams KD. Social loafing: A meta-analytic review and theoretical integration. J Pers Soc Psychol. 1993;65:681-706.

13. Kerr NL, Hertel G. The Köhler group motivation gain: How to motivate the "weak links" in a group. Soc Pers Psychol Comp. January 2010;5(1):43-55.

14. Weber B, Hertel G. Motivation gains of inferior group members: A metaanalytical review. J Pers Soc Psychol. 2007;93(6):973-93.

15. Steiner ID. Group process and productivity. New York: Academic Press; 1972.

16. Stroebe W, Diehl M, Abakoumkin G, eds. Social compensation and the Köhler effect: Toward a theoretical explanation of motivation gains in group productivity. Mahwah, NJ: Lawrence Erlbaum; 1996. Witte E, Davis J, eds. Understanding group behavior: Consensual action by small groups; No. 2 .

17. Kerr NL, Messé LA, Seok DH, Sambolec EJ, Lount Jr. RB, Park ES. Psychological mechanisms underlying the Köhler motivation gain. Pers Soc Psychol B. 2007;33(6):828-41.

18. Feltz DL, Kerr NL, Irwin BC. Buddy up: The Köhler effect applied to health games. J Sport Exerc Psychol. 2011;33:506-26.

19. U.S. Department of Health and Human Services. Physical activity and health: A report of the Surgeon General. Washington, D. C.2008. 
20. Lount Jr RB, Kerr NL, Messé LA, Seok DH, Park ES. An Examination of the Stability and Persistence of the KöhlerMotivation Gain Effect. Group Dynamics. 2008;12(4):279.

21. Clarke P, O'Malley PM, Johnston LD, Schulenberg JE, Lantz P. Differential trends in weight-related health behaviors among American young adults by gender, race/ethnicity, and socioeconomic status: 1984-2006. Am J Public Health. 2009;99(10):1893-901.

22. Bandura A. Guide for creating self-efficacy scales. In: Pajares F, Urdan T, eds. Self-efficacy beliefs of adolescents. Greenwich, CT: Informationa Age Publishing; 2006:307-37.

23. Mohiyeddini C, Pauli R, Bauer S. The role of emotion in bridging the intentionbehavior gap: The case for sports participation. Psychol Sport Exerc. 2009; 10:226-34.

24. Borg GAV. Borg's perceived exertion and pain scales. Champaign, IL: Human Kinetics; 1998.

25. Optenberg SA, Lairson DR, Slater CH, Russell ML. Agreement of self-reported and physiologically estimated fitness status in a symptom-free population. Prev Med. Jul 1984;13(4):349-54.

26. Troiano RP, Berrigan D, Dodd KW, Masse LC, Tilert T, McDowell M. Physical activity in the United States measured by accelerometer. Med Sci Sports Exerc. Jan 2008;40(1):181-8. 
27. Andrew GM, Oldridge NB, Parker JO, Cunningham DA, Rechnitzer PA, Jones NL, et al. Reasons for dropout from exercise programs in post-coronary patients. Med Sci Sports Exerc. 1981;13(3):164-8.

28. Williams SL, French DP. What are the most effective intervention techniques for changing physical activity self-efficacy and physical activity behaviour- and are they the same? Health Educ Res. 2011;26(2):308-22.

29. Weiner B. Human Motivation. NY: Holt, Rinehart \& Winston; 1980.

30. Kerr NL, Seok D, Poulsen J, Harris D, Messé LM. Social ostracism and group motivation gain. European Journal of Social Psychology. 2008;38(4):736-46.

31. Kerr NL, Seok DH. " ... with a little help from my friends": friendship, effort norms, and group motivation gain. Journal of Managerial Psychology. In press;26(3):205-18.

32. Huffmeier J, Hertel G. When the whole is more than the sum of its parts: Motivation gains in the wild. Journal of Experimental Social Psychology. in press. 